\section{"You Want To Go Where?" A Perspective on Skills and Competencies Developed through International Pharmacy Education Experiences}

Numerous articles have been published describing international rotations for entry-to-practice, resident, and graduate pharmacy students. ${ }^{1-10}$ I am currently completing the University of British Columbia's Graduate Doctor of Pharmacy program, which offers several elective international rotations. When selecting my electives, I sought advice from mentors and colleagues, who responded with skepticism about the academic value of international rotations. Despite some discouragement, I chose to complete 2 such rotations. The first 4-week rotation sent me to Doha, Qatar, for an academic leadership rotation, where my activities involved teaching and education-related projects. The second took place in rural Ghana, where 2 colleagues and I were immersed in the work of a rural hospital practice and small village medical clinic.

Fortunately, both rotations provided unparalleled opportunities for learning and personal development, most notablyfor me-in critical thinking, adaptability, and cultural humility. For example, my critical thinking ability was repeatedly tested in Ghana. Evidence-based medicine, the cornerstone of my current practice, was not always possible, because of a lack of appropriate diagnostic tools, laboratory tests, and drugs. For example, I had to determine whether to initiate antiplatelet therapy for a patient presenting with symptoms of stroke in the absence of imaging to rule out a bleed. After considering the risks and benefits and discussing possible outcomes with the patient's family, antiplatelet therapy was initiated with close monitoring of clinical symptoms. In this situation and others, I routinely had to draw on pharmacotherapy knowledge and utilize higher-level thinking to develop therapeutic plans for my patients.

Adaptability was a major learning aspect of both rotations. In Ghana, I adapted to practising without Internet access and to communicating with patients through translators and/or my limited knowledge of the local language. In Qatar, I had to think of creative techniques to assess understanding among students who wore a niqab (a veil worn by some Muslim women), which prevented me from reading their facial expressions.

Although I was certainly able to develop my skills as a clinician and educator, perhaps the most valuable trait I began to acquire on these rotations is cultural humility. Being immersed in cultures so radically different from my own has humbled me and forced me to reconsider my approach to situations where I am faced with cultural diversity or conflict. For example, when teaching Ghanaian students about contraception, I had to educate myself about widespread cultural beliefs and present the information in an appropriate and relevant manner, despite my strongly held personal belief that contraception use should be destigmatized and encouraged. My experience reinforced the importance of approaching patients with an open mind and being receptive to learning about their individual beliefs, values, and preferences. This insight will help me to provide competent care to all of my future patients, regardless of their cultural values and beliefs.

Many publications describing international rotations for pharmacy learners include an assessment of outcomes related to student development. ${ }^{1-10}$ These reports consistently demonstrate that students not only report a significant amount of personal growth from their experiences, but also gain compassion, adaptability, confidence, and skills to communicate and collaborate effectively. The cultural competency of students who complete these rotations also improves. ${ }^{2,3,7,8,10}$ The accreditation standards of the Canadian Council for Accreditation of Pharmacy Programs identify the ability to provide care to people of different cultures, values, beliefs, and customs as a requirement for entry-to-practice pharmacy graduates. ${ }^{11}$ The standards also include the goal of developing students who practise with compassion, are adaptable enough to work in a variety of settings, and can communicate and collaborate with other health care providers. Evidently, students who partake in international rotations are acquiring the skills and characteristics required for Canadian pharmacy graduates, and these rotations may provide an excellent environment for advanced development of these competencies.

There is no question that immersion in local health care settings is vital to educating pharmacists, but the unique competencies established on international rotations can complement the rigorous clinical and academic knowledge gained domestically. The benefits obtained by students who complete these rotations will depend on the quality, setting, and activities of the specific rotation, as well as each individual student's openness to embracing the challenges and opportunities involved. Nonetheless, it is reassuring that the literature consistently shows that students meet the objectives of accreditation bodies while abroad.

Given my own experience and the body of evidence supporting international pharmacy rotations, I encourage interested students to consider elective rotations abroad. These experiences can lead 
to the development of numerous invaluable competencies and may even be life-changing.

References

1. Flores KE, Courtney LA. Development of a partnership for international rural advanced pharmacy practice experiences. Int J Health Sci. 2014;2(1): article 5 .

2. Werrenmeyer AB, Skoy ET. A medical mission to Guatemala as an advanced pharmacy practice experience. Am J Pharm Educ. 2012;76(8):article 156.

3. Ward CT, Nemire RE, Daniel KP. The development and assessment of a medical mission elective course. Am J Pharm Educ. 2005;69(3):article 50.

4. Pauly JB, Poulakos MN, Fairclough JL, Chahine EB. Implementing and assessing an elective learning experience in medical missions for PGY-1 pharmacy residents. Curr Pharm Teach Learn. 2016;8(4):559-64. Also available from: http://dx.doi.org/10.1016/j.cptl.2016.03.017

5. Brown DA, Ferrill MJ. Planning a pharmacy-led medical mission trip, part 3: development and implementation of an elective medical missions advanced pharmacy practice experience (APPE) rotation. Ann Pharmacother. 2012; 46(7-8):1111-4.

6. Brown DA, Fairclough JL, Ferrill MJ. Planning a pharmacy-led medical mission trip, part 4: an exploratory study of student experiences. Ann Pharmacother. 2012;46(9):1250-5.

7. Gourley DR, Vaidya VA, Hufstader MA, Ray MD, Chrisholm-Burns MA. An international capstone experience for pharmacy students. Am J Pharm Educ. 2013;77(3):article 50.

8. Davis LI, Wright JD, Gutierrez MS, Nam JJ, Nguyen J, Waite AT. Interprofessional global service learning: a pharmacy and nursing practice experience in Botswana. Curr Pharm Teach Learn. 2015;7(2):169-78. Also available from: www.pharmacyteaching.com/article/S1877-1297(14) 00178-6/fulltext
9. Wietholter JP, Coetzee R, McCartney J, Gegg J, Schwinghammer TL. Development of an international advanced pharmacy practice experience (APPE) and lessons learned after implementation. Curr Pharm Teach Learn. 2014;6(2):304-12. Also available from: www.pharmacyteaching.com/ article/S1877-1297(13)00198-6/fulltext

10. Bress AP, Filtz MR, Truong HA, Nalder M, Vienet M, Boyle CJ. An advanced pharmacy practice experience in Melbourne, Australia: practical guidance for global experiences. Curr Pharm Teach Learn. 2011;3(1):53-62. Also available from: www.pharmacyteaching.com/article/S1877-1297(10) 00099-7/fulltext

11. Accreditation standards for the first professional degree in pharmacy programs. Toronto (ON): Canadian Council for Accreditation of Pharmacy Programs; 2014 [cited 2016 Jun 12]. Available from: http://ccapp-accredit.ca/wpcontent/uploads/2016/01/CCAPP_accred_standards_degree_2014.pdf

\section{Shaylee C Peterson, BScPharm, ACPR}

Graduate Doctor of Pharmacy student

Faculty of Pharmaceutical Sciences

The University of British Columbia

Vancouver, British Columbia

Competing interests: None declared.

Acknowledgements: Kyle J Wilby and Maria Paiva provided presubmission feedback and editing assistance.

\section{CISADL 2016}

\section{The 2016 Canadian Investigational \& Special Access Drug List is now on sale!}

\footnotetext{
Please use the CSHP Products \& Publications Order Form found online at CSHP.ca to place your order: http://www.cshp.ca/productsServices/otherPublications/canadian/nvestigational e.asp
}

The Canadian Investigational \& Special Access Drug List (CISADL) is a compilation of drugs that are currently not marketed in Canada, and may have investigational or special access status with Health Canada. This list is not endorsed by Health Canada's Special Access Program. For precise information about the regulatory status of a drug, contact the Special Access Program directly. Entries to the list are contributed to by several drug information centres across Canada and by Canadian drug manufacturers. In cases where non-marketed drugs do not appear on the list, foreign references should be consulted. The content of the list includes generic name and strength/concentration, dosage form, pharmacology/therapeutic use, trade and code name, source (manufacturer/distributor), and comments. Available in English only. 